\title{
Working
}

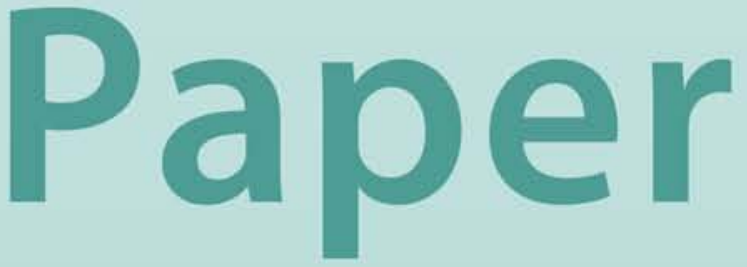


Central America's Regional Trends and

U.S. Cycles

Shaun K. Roache 


\title{
IMF Working Paper
}

\section{Central America's Regional Trends and U.S. Cycles}

\author{
Prepared by Shaun K. Roache \\ Authorized for distribution by Dominique Desruelle
}

February 2008

\begin{abstract}

\section{This Working Paper should not be reported as representing the views of the IMF.}

The views expressed in this Working Paper are those of the author(s) and do not necessarily represent those of the IMF or IMF policy. Working Papers describe research in progress by the author(s) and are published to elicit comments and to further debate.
\end{abstract}

The economies of Central America share a close relationship with the United States, with considerable comovement of GDP growth over a long period of time. Trade, the financial sector, and remittance flows are all potential channels through which the U.S. cycle could affect the region. But just how dependent is growth in the region on the U.S.? Using the common cycles method of Vahid and Engle (1993), this paper suggests that the business cycle is dominated by the U.S.; region-specific growth drivers tend to be long-lasting shocks, rather than temporary fluctuations. The most cyclically sensitive countries include Costa Rica, El Salvador, and Honduras.

JEL Classification Numbers:E32, F43

Keywords: business fluctuations, cycles, linkages

Author’s E-Mail Address: $\underline{\text { sroache@imf.org }}$

* I am grateful to David Gould, Nigel Chalk, Rodrigo Cubero, Dominique Desruelle, Judith Gold, Montie Mlachila, Par Osterholm, Jeromin Zettelmeyer, and seminar participants in the Western Hemisphere Department at the International Monetary Fund for comments and suggestions. 


\section{Contents}

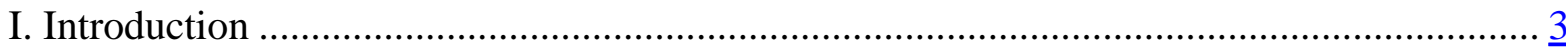

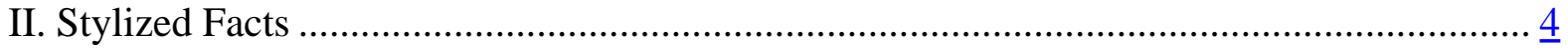

A. Trade Linkages...................................................................................................

B. Financial Linkages ...............................................................................................

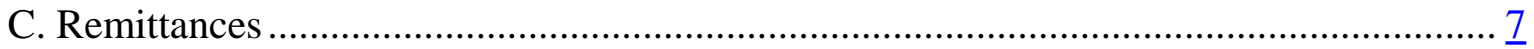

III. Literature Review.............................................................................................

A. Central America Linkages ……………………………...........................................

B. Common Business Cycles.......................................................................................... $\underline{9}$

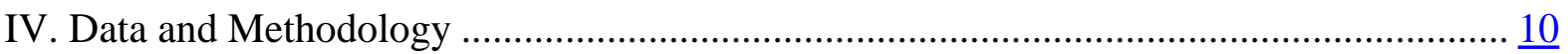

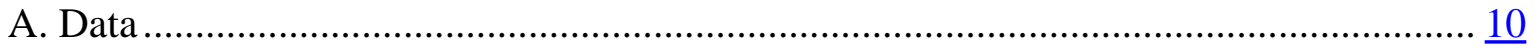

B. The Common Cycles Method ……………………………………………………... 10

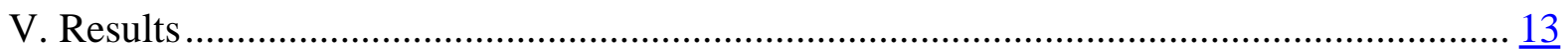

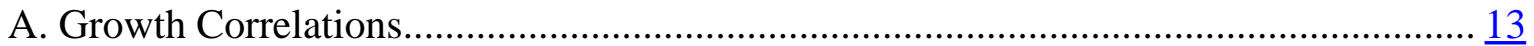

B. Four Common Trends and Three Common Cycles ………………………………….... 13

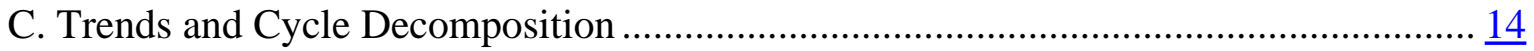

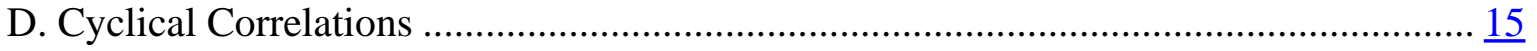

E. Cyclical and Trend Elasticities to the United States ..................................................... 18

F. Variance Decomposition by Factor ......................................................................... 19

VI. Summary and Concluding Remarks .............................................................................. 21

A. Cyclical Linkages_Stronger Than We Thought …………………………………….. 21

B. How Will Linkages Evolve? ..................................................................................... 21

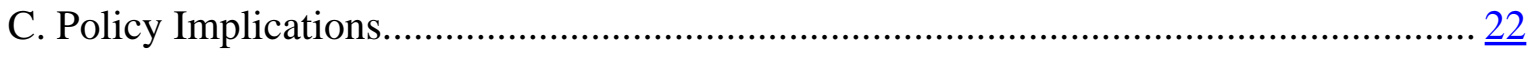

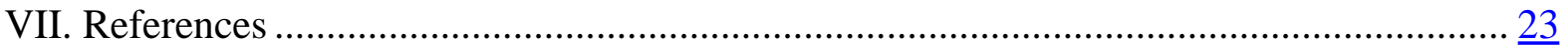

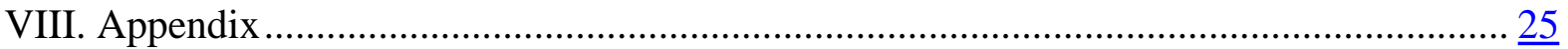




\section{INTRODUCTION}

The economies of Central America share a close relationship with the United States, with considerable comovement of GDP growth over a long period of time. The open nature of the region's economies, combined with geographical proximity to the U.S., have produced a number of transmission channels through which U.S. cyclical fluctuations can affect Central America. The trade channel is particularly important, with over half of all the region's merchandise exports over the preceding 5 years destined for the U.S., up from around onethird in the late 1990s (see Figure 1). Other possible channels include the financial sector, and remittance flows from migrant workers in the U.S., which accounted for 14 percent of regional GDP (excluding Panama) during 2006.

We can see from Figure 1 that there are links between Central America and the U.S. economy; but just how dependent is growth in the region on the U.S.? Is there some part of the economic cycle which is uniquely Central American? If not, what explains those periods during which certain economies appear to have decoupled from the U.S.? We will attempt to answer those questions here. The framework is an application of the common cycles method of Vahid and Engle (1993), which applies the insights of cointegration to the analysis of stationary, or in our case, cyclical economic data.

We proceed as follows: Section II describes some stylized facts about economic linkages between Central America and the U.S.; Section III briefly reviews the literature; Section IV discusses data and methodology; Section V presents the results; and Section VI gives some concluding remarks.

Figure 1. Central America: GDP growth, 1970-2006
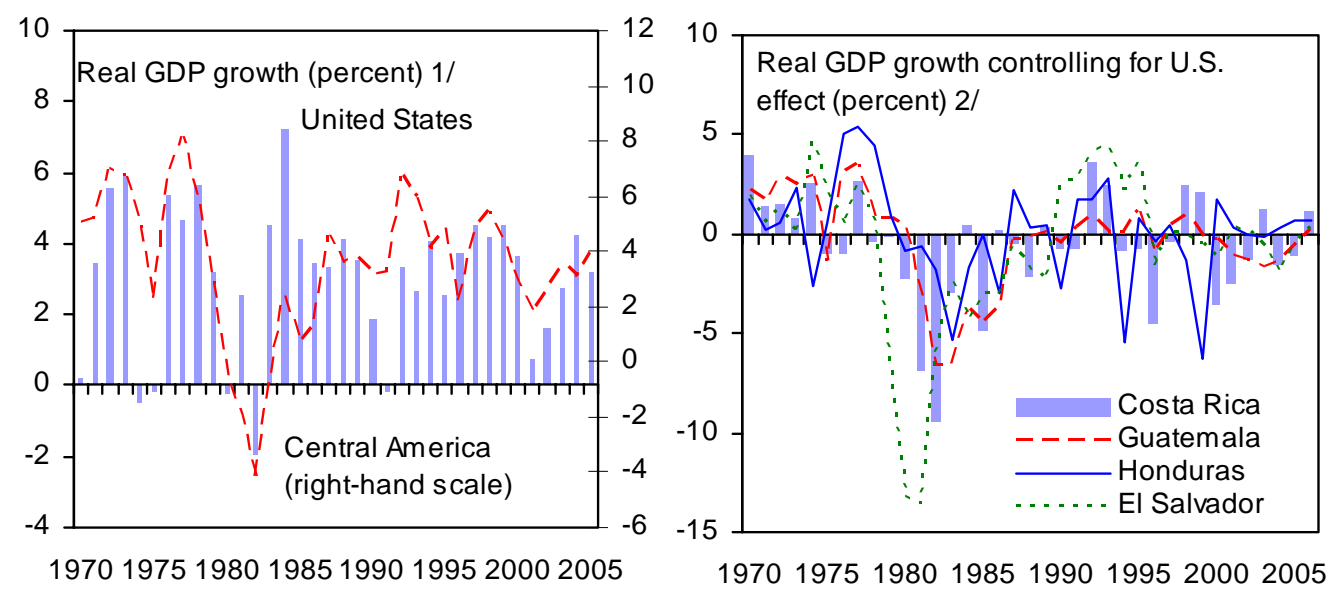

Sources: International Financial Statistics; author's calculations.

1/ Weighted average excluding Nicaragua and Panama.

2/ Residuals from an OLS regression of country GDP growth on U.S. GDP growth. 


\section{STYLIZED F ACTS}

Three channels of transmission are commonly thought to explain the close economic relationship between Central America and the United States: trade; the financial sector; and remittances. In this section, we will present some facts about all three of these areas.

\section{A. Trade Linkages}

Trade is likely to have been the most important linkage. Since the early 1980s, the share of total merchandise exports from the region as a whole to the United States has averaged around 40 percent, ranging from 27 percent in Nicaragua to 53 percent in Honduras. ${ }^{1}$ The second largest share is exports to other Central American countries, which has averaged around 20 percent over the same period. Do exports to the region help to diversify exposure away from the U.S. economy? The answer is "yes" in two circumstances: either there exists a unique Central American business cycle or there is divergence in the long-run rate of trend growth between the region and the U.S., an issue that we be explored below. The two possibilities would have very different implications for both the behavior of exports and the overall economy given that exports accounted for 20 percent of regional GDP in 2006.

\section{B. Financial Linkages}

Financial linkages are important, due in part to the high, albeit varying, degrees of dollarization across Central America. With many transactions taking place in U.S. dollars, financial conditions in the U.S. and the region should share some similarities, most obviously in terms of interest rates. The obvious rejoinder is that, as economists have known for some time, real interest rate parity, as described in theory, has little evidence to support it, despite open capital accounts. ${ }^{2}$ Indeed, complete interest rate synchronization rarely holds between Central America and the U.S., even for officially dollarized economies such as El Salvador, perhaps reflecting some frictions and other imperfections in the financial sector.

\footnotetext{
${ }^{1}$ The figures in this section refer to exports of goods and exclude services. This is an increasingly important component of exports for some countries, particularly for those economies with a large and developing tourist industry such as Costa Rica.

${ }^{2}$ These results have been based largely on short-horizon data. Recent work — see Chinn and Meredith (2005)— suggests that the relationship may be stronger for long-term interest rates.
} 
Figure 2. Destination of Exports (percent of total exports) 1986 Q1 - 2007 Q2 1/
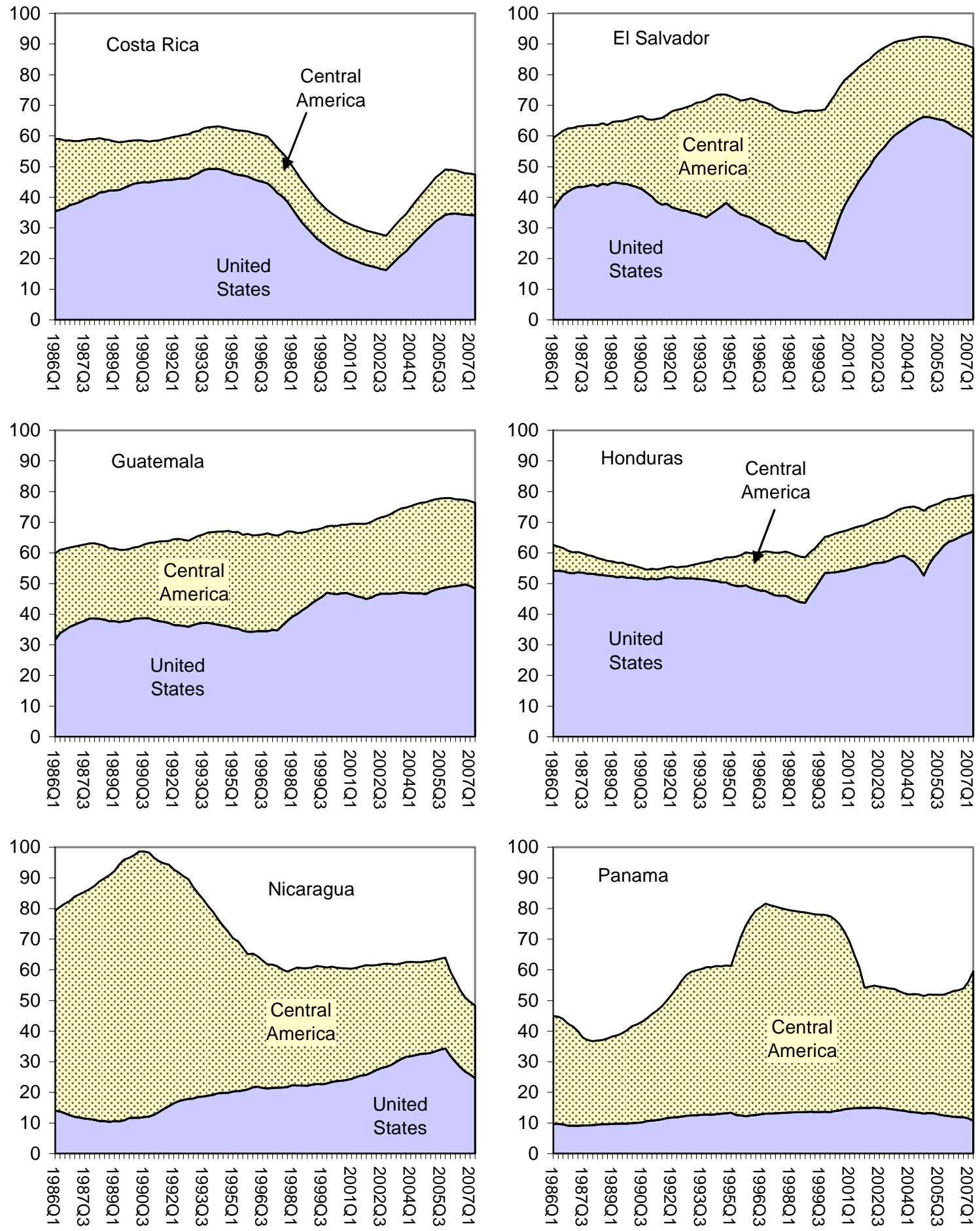

Source: IMF Direction of Trade Statistics.

$1 /$ Rolling five-year sum of quarterly export data. 
Figure 3. Central America: External Debt Owed to BIS-reporting Foreign Banks by Domicile (percent of GDP 1995-2006)
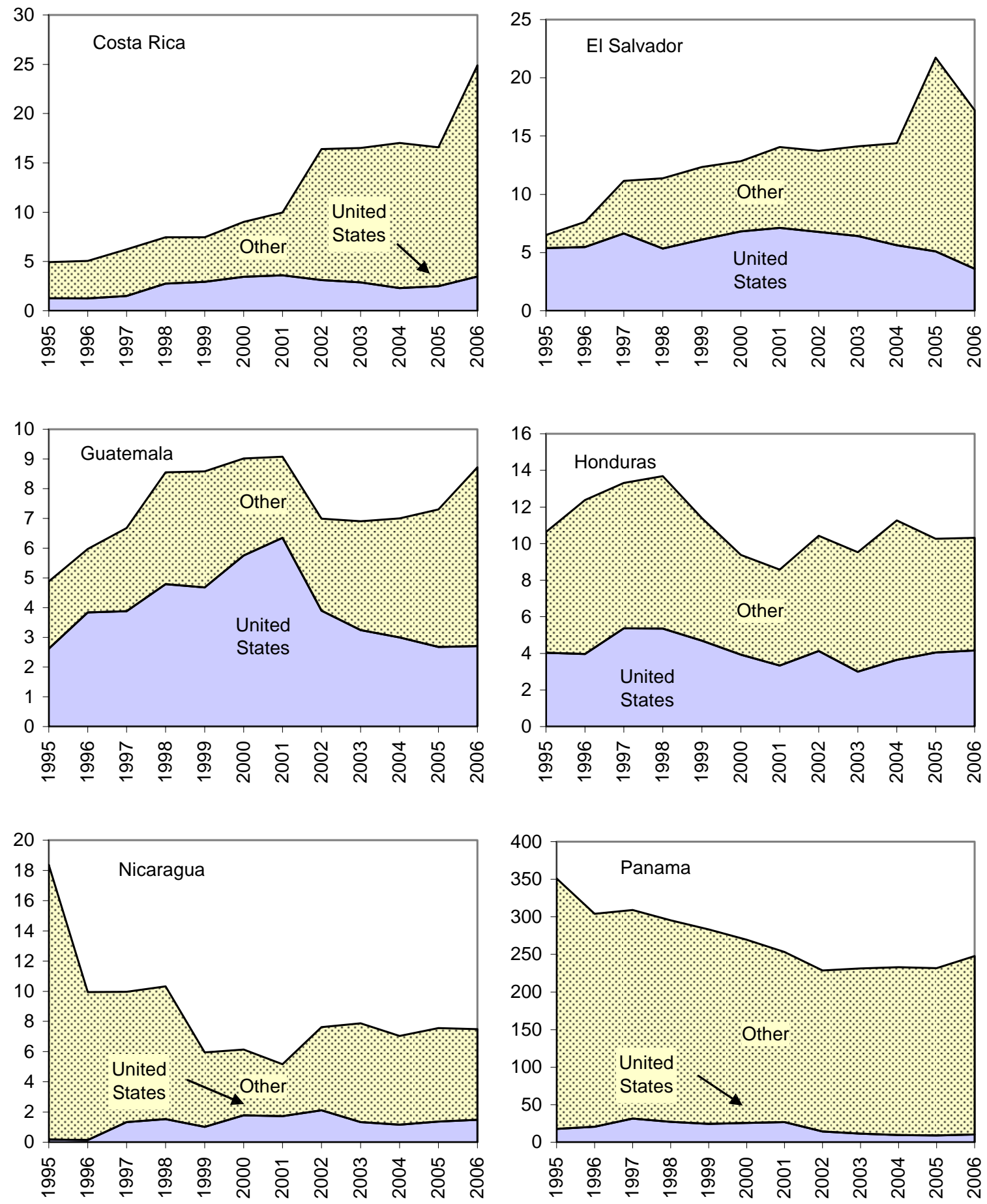

Source: Bank for International Settlements. 
A more direct linkage with U.S. financial conditions is through external debt. The debt owed to foreign banks that report to the Bank of International Settlements (BIS) by Central American borrowers from all sectors (excluding Panama) accounted for around 15 percent of GDP at the end of 2006. ${ }^{3}$ Just over 3 percent of GDP is owed to U.S. banks, with much of the remainder also likely to be U.S. dollar denominated given the pattern of trade flows-see Figure 3. Loans with a maturity of less than one-year - on which interest rates are set frequently, reflecting prevailing global financial conditions-account for almost half of outstanding claims by BIS banks on Central America.

Foreign ownership of domestic banks - referring here to institutions from outside of the region-may also introduce spillovers, particularly if these institutions take a global view of their portfolio and formulate their policies on the basis of financial conditions in their domicile economy. The degree of foreign ownership varies widely across the regions from less than 15 percent in Guatemala to over 90 percent in El Salvador. Even before the large scale entry of foreign banks, financial sector integration had gained momentum over the past few years as some regional institutions that originally focused on the home market expanded, as noted by Morales and Schipke (2003). The large scale entry of foreign banks is also a relatively new development in some countries and it is not yet clear how financial sector linkages will be affected.

\section{Remittances}

Remittance flows sent by migrant workers to Central America have grown rapidly in recent years and, for some countries, now account for a significant share of GDP and rival or even dwarf FDI as a source of external financing-see Table 1. Over the long term, sociodemographic and institutional factors, in the host and recipient countries, are likely to have a dominant influence. However, in the short term, it is reasonable to presume that cyclical economic conditions in the host country would influence these remittance flows.

A number of theoretical models that describe remittance behavior have been proposed - see Rapoport and Docquier (2005) for a survey - but recent empirical evidence from Roache and Gradzka (2007) suggests that this may not have been an important source of spillovers from the U.S. up until now. Notwithstanding weaknesses in the remittances data, this could be due to migrant workers "smoothing" their remittance flows, for example, by sending a fixed U.S. dollar amount each month or quarter, irrespective of income fluctuations, within reason. An alternative explanation is that immigrants attach more weight to being employed than to the wage received, and thus are less likely to be unemployed (cetirus paribus) than their native-born counterparts.

\footnotetext{
${ }^{3}$ These figures exclude Panama due to the scale of that financial system's offshore activities. These figures also exclude local lending by foreign banks that have acquired a presence in domestic banking systems.
} 
Table 1. Comparing the Size of Remittances, 2006

\begin{tabular}{|c|c|c|c|c|c|}
\hline & \multirow[b]{2}{*}{$\begin{array}{c}\text { U.S. dollars } \\
\text { billions }\end{array}$} & \multirow{2}{*}{$\begin{array}{c}\text { Percent } \\
\text { change since } \\
2000 \\
\end{array}$} & \multicolumn{3}{|c|}{ Percent of } \\
\hline & & & GDP & $\begin{array}{c}\text { FDI } \\
\text { inflows }\end{array}$ & $\begin{array}{c}\text { Exports of } \\
\text { G\&S }\end{array}$ \\
\hline Costa Rica & 0.5 & na & 2.3 & 74 & 4 \\
\hline El Salvador & 3.3 & 89 & 18.1 & 667 & 69 \\
\hline Guatemala & 3.6 & 541 & 10.2 & 1,111 & 66 \\
\hline Honduras & 2.2 & na & 25.0 & 774 & 60 \\
\hline Nicaragua & 0.7 & 105 & 12.2 & 235 & 28 \\
\hline
\end{tabular}

Sources: National authorities; International Financial Statistics; author's calculations.

\section{LITERATURE REVIEW}

The relevant literatures for our purposes include: (i) Central American economic linkages; and (ii) applications of the codependence methodology to business cycles. We will briefly review what little work has been done in both areas.

\section{A. Central America Linkages}

While the results from global and broader regional studies indicate that Central America is one of the more globally integrated regions of the world - e.g. IMF (2007)-little work has been done specifically on the region. One of the most comprehensive is Fiess (2007), who measures business cycle synchronization in Central America and sensitivity to the United States initially using simple correlations of band-pass filtered GDP data from 1965-2002. There is evidence of a close relationship between Costa Rica, El Salvador, Guatemala, and Honduras and between this group and the U.S., suggesting that a significant portion of variability is being driven by external factors. The other two countries, Nicaragua and Panama, exhibit low, or even negative, correlations in most cases. Controlling for the common effect of the U.S. causes correlations to decline, although they remain fairly high between Costa Rica and Guatemala (0.48), Costa Rica and El Salvador (0.41), and Guatemala and Honduras (0.42).

This paper also presents coherence measures over assumed business cycle frequencies of 6 to 32 quarters for Central America using industrial production and other monthly indicators from the 1995-2003 period. These results tend to confirm those from simple correlations. Business cycle synchronization was highest between Costa Rica and El Salvador (0.53), El Salvador and Guatemala (0.53), El Salvador and Nicaragua (0.51), and Honduras and Nicaragua (0.55). Comparing the CAFTA trade blocs to others, it was shown that intraCAFTA coherence was lower than that seen within NAFTA and the European Union but similar to that within Mercosur.

Kose and Rebucci (2005) estimated country-specific vector autoregressions for 5 Central American economies, the Dominican Republic, and Mexico using data over 1964-2003. Six shocks are assumed to drive business cycle dynamics, three domestic and three external. The domestic variables include real GDP growth, the CPI inflation rate, and the trade balance-toGDP ratio. External variables include U.S. real GDP growth, a measure of the ex-post U.S. real interest rate, and the ratio of oil to nonfuel commodity prices (a proxy for the terms 
of trade). External shocks accounted for one-third of output variance, with a wide range across economies from Costa Rica (67 percent) and Guatemala (55 percent) to the Dominican Republic (10 percent) and Nicaragua (18 percent).

They also present multi-country VARs using GDP growth rates for the U.S., Mexico, and the same six regional economies above, assessed the importance of regional shocks. The block recursive structure placed the U.S. and Mexico in the first block, five Central American countries in the second, and the regional economy of interest in the final block. With this setup, NAFTA shocks explained an average of 22 percent of output variance for regional economies, with Honduras (34 percent), Costa Rica, and El Salvador (both at 26 percent) showing most sensitivity. Regional shocks were more important, explaining on average $1 / 2$ of output variance, with the range across countries much tighter. Domestic shocks explained the remainder (24 percent), with the Dominican Republic and Nicaragua most affected by idiosyncratic disturbances.

\section{B. Common Business Cycles}

Cerro and Pineda (2000) apply the codependent approach to investigate real output trend and cycle dynamics for 11 Latin American economies using quarterly constant price GDP data from 1960-2000. ${ }^{4}$ Tests indicated the existence of 7 common trends and 4 common cycles, allowing the decomposition into trend and cycle components. The correlations of the cyclical components show that correlations across the region peaked in the 1970-80 decade, declined through 1980-90, but have been rising since then. While intra-regional correlations appear high compared to the results from other studies (often above 0.5), there was little evidence that either Chile or Mexico were influenced by the common regional cycle.

Hecq, Palm, and Urbain (2005) test for the presence of comovements in annual GDP series for five Latin American countries-Brazil, Argentina, Mexico, Peru, and Chile, for the period 1950-1999. The main purpose of this study is to develop a test for strong and weak form reduced rank structures, with the first referring to the existence of common cycles within first-differenced data and the latter within first differences adjusted for long-run effects. They find evidence for 2 to 3 cointegrating vectors and 3 codependent vectors (of each kind, strong and weak form), depending upon the specification, indicating linkages across the economies. The reduced form restrictions implied by a common cycle structure also appear to improve model accuracy, on the basis of root mean-squared errors.

Hecq (2005) uses annual GDP data over 1950-2002 for six Latin American countries (Brazil, Chile, Colombia, Peru, Mexico, and Venezuela), and finds 3 common trends and 3 common cycles. This paper provides an innovation by using an iterative approach to improve the performance of the Johansen test in small samples, and concentrates more on the method than the results.

\footnotetext{
${ }^{4}$ Countries include Argentina, Bolivia, Brazil, Chile, Colombia, Ecuador, Mexico, Paraguay, Peru, Uruguay, and Venezuela. Imports were used to interpolate the GDP series when quarterly data were not available.
} 


\section{Data AND Methodology}

\section{A. Data}

We use annual real GDP from 1950-2006 for six Central American countries-Costa Rica, El Salvador, Guatemala, Honduras, Nicaragua, and Panama-and the United States. The data are taken from International Financial Statistics and, for earlier periods, the Penn World Tables. Summary statistics for this data in annual percent changes are presented in Table 2 with a more detailed summary in Table A1. For advanced economies, much use has been made of quarterly data and, while this is usually preferable for analyses of business cycles, it remains difficult to obtain data at this frequency that is both comparable across countries and available with a sufficient history for the Central America region.

Table 2. Real GDP Growth - Summary Statistics

\begin{tabular}{|c|c|c|c|c|c|c|c|c|}
\hline & \multicolumn{4}{|c|}{$1951-2006$} & \multicolumn{4}{|c|}{ 1995-2006 } \\
\hline & Mean & $\begin{array}{l}\text { Standard } \\
\text { deviation }\end{array}$ & Max. & Min. & Mean & $\begin{array}{l}\text { Standard } \\
\text { deviation }\end{array}$ & Max. & Min. \\
\hline Costa Rica & 5.4 & 4.1 & 18.4 & -7.3 & 4.8 & 2.7 & 8.4 & 0.9 \\
\hline El Salvador & 3.3 & 4.0 & 12.0 & -11.8 & 3.1 & 1.4 & 6.4 & 1.7 \\
\hline Guatemala & 3.9 & 2.5 & 9.5 & -3.5 & 3.5 & 0.9 & 4.9 & 2.4 \\
\hline Honduras & 3.8 & 4.0 & 17.9 & -8.6 & 3.6 & 2.1 & 6.0 & -1.9 \\
\hline Nicaragua & 3.2 & 6.4 & 15.0 & -26.5 & 4.2 & 1.7 & 7.0 & 0.8 \\
\hline Panama & 4.7 & 4.8 & 18.7 & -13.4 & 4.5 & 2.6 & 8.1 & 0.6 \\
\hline
\end{tabular}

Sources: Penn World Tables; International Financial Statistics; National authorities.

As the literature shows, there are many methods available to assess linkages and common cycles across economies. The focus in this paper is on two of those methods: simple correlations, using a variety of cyclical decompositions; and the common cycles approach first described by Engle and Kozicki (1992).

These methods are intuitive and provide a clear description of the common forces that drive business cycle fluctuations. The results are easy to interpret, can be compared against those of other well-known methods of business cycle analysis, and allow for the testing of hypotheses. As with any methodology, there are drawbacks and the most important of these is the emphasis on association rather than causation. These methods have little, or nothing, to say explicitly regarding the underlying economic forces that drive synchronization. Some interpretation can be imposed upon the results, but this will be more conjecture than firm conclusion.

\section{B. The Common Cycles Method}

The common cycles technique is an extension of the cointegration framework outlined by Johansen (1988). Cointegration implies that one or more linear combinations of nonstationary variables can remove the trend from the data. As shown by Stock and Watson (1988), for $n$ variables, the existence of $r$ cointegrating vectors implies the existence of $n-r$ 
common stochastic trends. For economic output series, one interpretation of this result could be that, over the long-run, there exist common forces driving the underlying growth process.

An analogous indicator of comovement among nonstationary series is codependence. A strong form of codependence is the serial correlation feature as described by Engle and Kozicki (1993). In this case, there exist some linear combinations of the variables that remove correlations, and hence predictability, based on the set of past values. These linear combinations are defined as cofeature vectors and may be compared to cointegration vectors for stationary data. The approach briefly described below borrows from Vahid and Engle (1993), where full technical details of the theory are presented.

Let $\mathbf{y}_{t}$ denote the $(7 \times 1)$ vector of log GDP series for the economies in our sample. As confirmed by standard tests (Table A1), these data are I(1) while their first differences $\Delta \mathbf{y}_{t}$ are $\mathrm{I}(0)$. As a result, $\Delta \mathbf{y}_{t}$ has a Wold representation:

$$
\Delta \mathbf{y}_{t}=\mu+\mathbf{C}(L) \boldsymbol{\varepsilon}_{t}
$$

Where $\boldsymbol{C}(L)$ is a matrix polynomial in the lag operator and $\boldsymbol{\varepsilon}$ is an $(7 \times 1)$ vector of stationary innovations. Assuming that $\mu=0$ for algebraic convenience, the Beveridge-Nelson decomposition allows the original I(1) series to be expressed as the sum of a trend $(T)$ and a cyclical $(C)$ component.

$$
\mathbf{y}_{t}=\mathbf{C}(1) \sum_{s=0}^{\infty} \boldsymbol{\varepsilon}_{t-s}+\mathbf{C}^{*}(L) \boldsymbol{\varepsilon}_{t-s}=T_{t}+C_{t}
$$

Stock and Watson (1988) showed that a number of common trends $r$ may be shared among the variables in vector $\mathbf{y}$. In this case, the matrix $\mathbf{C}(1)$ may be decomposed into the product of an $(n \times(n-r))$ matrix of rank $n-r(\mathrm{~A})$ with a $((n-r) \times n)$ matrix of rank $n-r(\mathrm{~B})$ as follows:

$$
\mathbf{y}_{t}=\mathbf{A B} \sum_{s=0}^{\infty} \boldsymbol{\varepsilon}_{t-s}+\mathbf{C}^{*}(L) \boldsymbol{\varepsilon}_{t-s}=\mathbf{A} \mathbf{Z}_{t}+\mathbf{C}_{t}
$$

Where $\mathbf{A}$ is a $(n \times(n-r))$ matrix of factor loadings with full column rank. Analogously, the vector $\mathbf{y}$ may also share common cycles. If common cycles exist, then there must exist linear combinations of the $\mathbf{y}$ vector which do not contain the cycle and for which history has no predictive power. This would imply that the following condition, for some set of linearly independent vectors $\boldsymbol{\alpha}^{*}$ known as co-feature vectors, will hold:

$$
\boldsymbol{\alpha}^{* /} \mathbf{C}_{t}=0
$$

When applied to $\Delta \mathbf{y}$ the cofeature transformation $\boldsymbol{\alpha}^{*}$ eliminates all the positive powers of the lag operator; in other words, it removes the serial correlation of first-differences. This same transformation, when applied to the levels, removes the common cycles. 
We test for the existence of common cycles using the canonical correlation procedure outlined in Vahid and Engle (1993). The first step is to estimate a vector error correction model to recover the error correction series, otherwise known as the long-run relationship:

$$
\Delta \mathbf{y}_{t}=\boldsymbol{\Phi} \mathbf{y}_{t-1}+\sum_{s=1}^{p} \boldsymbol{\Gamma}_{s} \Delta \mathbf{y}_{t-s}+\boldsymbol{\varepsilon}_{t}
$$

Then, defining two $(7 \times 1)$ random vectors $\boldsymbol{\rho}_{\boldsymbol{t}}$ and $\boldsymbol{\eta}_{\boldsymbol{t}}$, which are linear combinations of the ( 7 $\mathrm{x} 1)$ vector $\Delta \mathbf{y}_{t}$ and the $((7 p+r) \mathrm{x} 1)$ vector of lags and error correction terms (which will be termed $\mathbf{x}_{t}$ :

$$
\begin{aligned}
& \boldsymbol{\rho}_{t}=\mathbf{A}^{\prime} \Delta \mathbf{y}_{t}
\end{aligned}
$$

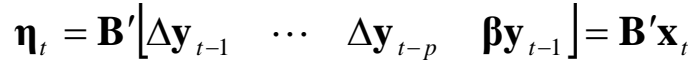

The $(n \times n)$ matrix $\mathbf{A}$ and the $(n \times(n p+r))$ matrix $\mathbf{B}$ are chosen such that four conditions hold. The first two state that the individuals elements of both $\boldsymbol{\rho}_{\boldsymbol{t}}$ and $\boldsymbol{\eta}_{t}$ have unit variance; the third condition states that the ith element of $\boldsymbol{\rho}_{\boldsymbol{t}}$ and the $j$ th element of $\boldsymbol{\eta}_{t}$ are uncorrelated; and the final condition states that the elements of $\boldsymbol{\rho}_{\boldsymbol{t}}$ and $\boldsymbol{\eta}_{t}$ are ordered in such a way such that:

$1 \geq \lambda_{1} \geq \cdots \geq \lambda_{n} \geq 0$

Where the correlation $r_{i}$ is known as the ith canonical correlation between the two vectors $\Delta \mathbf{y}_{\boldsymbol{t}}$ and $\mathbf{x}_{t}$. The canonical correlations and the values of $\mathbf{A}$ and $\mathbf{B}$ can be calculated from the covariance matrices of $\Delta \mathbf{y}_{t}$ and $\mathbf{x}_{t}$ through eigenvalues and eigenvectors. The test statistic is analogous to the trace statistic from the Johansen procedure, with the null hypothesis that the dimension of the cofeature space is at least $s$ (or equivalently that there are at most $n-s$ common cycles) is:

$$
C(p, s)=-(T-p-1) \sum_{i=1}^{s} \log \left(1-\lambda_{i}^{2}\right)
$$

where the $\lambda^{2}$ 's are the $s$ smallest squared canonical correlations between $\boldsymbol{\rho}_{t}$ and $\boldsymbol{\eta}_{t}$. Under the null, this statistic is chi-squared with $s^{2}+s n p+s r-s n$ degrees of freedom.

Suppose there are $s$ linearly independent cofeature vectors; in this case, the ( $s \times n$ ) matrix of cofeature vectors that has full column rank. Vahid and Engle (1993) suggest that these equations may be regarded as $s$ pseudo-structural equations for the first $s$ terms of the vector $\Delta \mathbf{y}:$

$$
\tilde{\boldsymbol{\alpha}}^{\prime} \Delta \mathbf{y}_{t}=\mathbf{v}_{t}
$$

In other words, there are $s$ linearly independent combinations of the elements of $\Delta \mathbf{y}_{t}$ which have no dependence on the relevant past, such that the residual term is stationary, analogous to cointegration. The system is completed by including the unconstrained reduced-form equations for the remaining $(n-s)$ elements of the $(n \times 1)$ vector. 


$$
\left[\begin{array}{cc}
\mathbf{I}_{s} & \tilde{\boldsymbol{\alpha}}^{\prime} \\
\mathbf{0}_{(n-s) \times s} & \mathbf{I}_{n-s}
\end{array}\right] \Delta \mathbf{y}_{t}=\left[\begin{array}{c}
\mathbf{0}_{s \times(n p+r)} \\
\boldsymbol{\Pi}_{1}^{*}, \ldots, \boldsymbol{\Pi}_{1}^{*} \beta^{*}
\end{array}\right] \cdot\left[\begin{array}{c}
\Delta \mathbf{y}_{t-1} \\
\\
\Delta \mathbf{y}_{t-p} \\
\tilde{\boldsymbol{\alpha}}^{\prime} \mathbf{y}_{t-1}
\end{array}\right]+\mathbf{v}_{t}
$$

This system may then be estimated using maximum likelihood or other estimation procedures, such as iterative three-stage least squares.

\section{REsults}

\section{A. Growth Correlations}

Surprisingly, correlations of GDP growth rates are neither particularly high, nor statistically significant, in many cases - see Table 3. There is a cluster of economies-Costa Rica, El Salvador, and Guatemala - that correlate fairly closely, but the links do not appear to be too strong. Even to the United States, correlations appear to be low and, for some economies, have not risen in the latest decade or so.

One possible interpretation is that linkages are weak. A second, more plausible, alternative given the stylized facts presented in Section II is that GDP growth rates are a combination of changes in the trend and cycle and that the linkages of both components differ.

\section{B. Four Common Trends and Three Common Cycles}

The first step in the common cycle approach is to select the lag order of the system by identifying the vector autoregression — using nonstationary level data - with the lowest Aikake information criteria (AIC). ${ }^{5}$ A 5 lag system was selected by the AIC and other criteria (Table A2). If the series are cointegrated, this implies an error-correction representation with 4 lags and this was used as the basis for the cointegration tests.

Cointegration tests, run on a number of lag specifications for robustness, suggest 3 cointegrating vectors, which implies 4 common trends among the GDP series. Table A3 shows the results of the cointegration tests at the 5 percent level of significance and also indicates one weakness of the Johansen methodology with small samples and overparameterization (see Cheung and Lai (1993) and Ho and Sorensen (1996) among

\footnotetext{
${ }^{5}$ Although the AIC possesses a nonzero limiting probability of overfitting a VAR model—that is selecting too many lags-Gonzalo and Pitarakis (2000) have shown that this bias is a decreasing function of the system dimension and that the AIC outperforms other criteria in large dimensional systems. Also, Hecq, Palm and Urbain (2005) have shown that the inefficiencies of overfitting a common cycles model tend to be small.
} 
Table 3. Central American GDP Growth Correlations, 1950-2006 and 1995-2006 1/

\begin{tabular}{|c|c|c|c|c|c|c|c|c|c|c|c|c|}
\hline & \multicolumn{6}{|c|}{$\begin{array}{l}\text { Correlation of GDP growth rates } \\
\text { including the United States }\end{array}$} & \multicolumn{6}{|c|}{$\begin{array}{l}\text { Correlation of GDP growth rates } \\
\text { controlling for the U.S. effect } 2 /\end{array}$} \\
\hline & $\begin{array}{l}\Omega \\
0 \\
0 \\
D \\
D \\
\bar{\Omega}\end{array}$ & 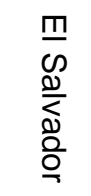 & 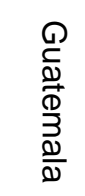 & 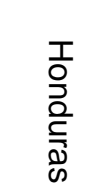 & 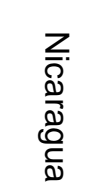 & 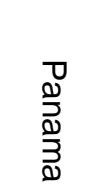 & 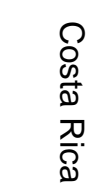 & 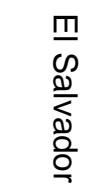 & 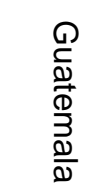 & 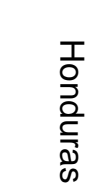 & 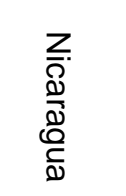 & 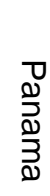 \\
\hline & \multicolumn{12}{|c|}{$1950-2006$} \\
\hline El Salvador & 0.54 & & & & & & 0.47 & & & & & \\
\hline Guatemala & 0.38 & 0.39 & & & & & 0.36 & 0.37 & & & & \\
\hline Honduras & 0.12 & 0.26 & 0.44 & & & & 0.01 & 0.15 & 0.42 & & & \\
\hline Nicaragua & 0.13 & 0.33 & 0.10 & -0.21 & & & 0.13 & 0.34 & 0.10 & -0.24 & & \\
\hline Panama & 0.21 & 0.13 & 0.09 & -0.07 & 0.23 & & 0.23 & 0.14 & 0.09 & -0.07 & 0.23 & \\
\hline \multirow[t]{2}{*}{ United States } & 0.34 & 0.37 & 0.13 & 0.35 & 0.05 & 0.00 & & & & & & \\
\hline & \multicolumn{12}{|c|}{$1995-2006$} \\
\hline El Salvador & 0.47 & & & & & & 0.30 & & & & & \\
\hline Guatemala & 0.63 & 0.79 & & & & & 0.58 & 0.68 & & & & \\
\hline Honduras & -0.23 & 0.06 & 0.06 & & & & -0.32 & 0.16 & 0.02 & & & \\
\hline Nicaragua & 0.09 & 0.26 & 0.04 & -0.25 & & & -0.10 & -0.05 & -0.10 & -0.42 & & \\
\hline Panama & 0.71 & 0.16 & 0.49 & 0.32 & 0.07 & & 0.60 & -0.19 & 0.39 & 0.10 & 0.02 & \\
\hline United States & 0.49 & 0.21 & 0.32 & 0.01 & 0.59 & 0.63 & & & & & & \\
\hline
\end{tabular}

Source: Author's calculations

1/ Figures in bold are statistically significant at the 5 percent level.

$2 /$ These correlation coefficients use residuals from a regression of country i's growth rate on

a constant and the United States growth rate, over the same sample period.

others). Often, the likelihood ratio tests are too liberal, leading to an overestimate of the number of cointegrating vectors $r$ and this bias is magnified as the lag length increases.

The test for common cycles is based on calculating the canonical correlations of the ( $7 \mathrm{x} 1)$ vector $\Delta \mathbf{y}_{t}$ and its lagged values and the first lag of the 3 error correction terms. The value of the test statistic described by equation (8) are presented in Table A3. In this test, the null hypothesis is that there are at least $n-s$ common cycles and, at the 5 percent level of significance, it was not possible to reject the hypothesis of 4 common cycles among the GDP series. This conclusion was insensitive to the number of cointegrating relationships. Also, in most cases, the combined number of cointegration and cofeature vectors spanned $R^{n}$, i.e. $r+$ $s=n$.

\section{Trends and Cycle Decomposition}

When the number of cycles and trends sum to the number of variables-i.e. $r+s=n$-we have a special case that allows us to decompose each GDP series into a separate trend and cycle component. This Beveridge-Nelson-style decomposition of the $\mathbf{y}_{t}$ vector into permanent 
(trend) and transitory (cyclical) components can be derived for each country, as shown by Vahid and Engle (1993) and extended in Gonzalo and Granger (1995).

The first step in recovering these components is to estimate the system described by equation (10). This was estimated using iterative 3-stage least squares, which accounts for endogeneity of some regressors and provides efficiency gains over the two-stage procedure due to the existence of common exogenous shocks-for example, the oil price-on output. We now have estimates for the cointegrating and cofeature vectors.

To see how these estimates may be used to recover the trends and cycles, recall that a cointegrating combination of I(1) variables eliminates the trend from the data, leaving only the cycle. By analogy, a codependent combination of the same variable eliminates the cycle, leaving only the trend. As a result, the following terms describe the trend and cyclical factors, respectively:

$\tilde{\boldsymbol{\alpha}}^{\prime} \mathbf{y}_{t}=\tilde{\boldsymbol{\alpha}}^{\prime} \mathbf{C}(1) \sum_{s=0}^{\infty} \boldsymbol{\varepsilon}_{t-s}$

$\boldsymbol{\alpha}^{\prime} \mathbf{y}_{t}=\boldsymbol{\alpha}^{\prime} \mathbf{C}^{*}(L) \boldsymbol{\varepsilon}_{t-s}$

Where $\tilde{\boldsymbol{\alpha}}$ is the ( $n \times s)$ matrix of cofeature vectors and $\boldsymbol{\alpha}$ is the ( $n \times r)$ matrix of cofeature vectors. The trend and cycle for each series can then be recovered using the following expression, where the ( $n \times s)$ matrix $\tilde{\boldsymbol{\alpha}}^{-}$and $(n \times r)$ matrix $\boldsymbol{\alpha}^{-}$are formed from the partition of the inverse of the matrix $\left[\begin{array}{ll}\tilde{\boldsymbol{\alpha}}^{\prime} & \boldsymbol{\alpha}^{\prime}\end{array}\right]^{\prime}$ :

$\mathbf{y}_{t}=\tilde{\boldsymbol{\alpha}}^{-} \tilde{\boldsymbol{\alpha}}^{\prime} \mathbf{y}_{t}+\boldsymbol{\alpha}^{-} \tilde{\boldsymbol{\alpha}}^{\prime} \mathbf{y}_{t}=$ trend + cycle

Figures 3 and 4 show the derived trends and cycles to their HP-filter counterparts. One cautionary note regarding the common cycle model is the relatively high volatility of the trend component, a tendency also seen in the original application to U.S. consumption by Vahid and Engle (1993). Trend or underlying, GDP growth is often assumed to be smooth over time, with a lower frequency of peturbations.

As a robustness check, the model was also run assuming 4 shared cycles and 3 shared trends. The results were not qualitatively different, although for some countries, the cycle tended to be somewhat more volatile. This is particularly true for Guatemala, for which the low volatility of the official GDP series tends to imply a very shallow cycle with this model.

\section{Cyclical Correlations}

Correlations of the cyclical part of GDP from this model are much higher than for the annual growth rate or the H-P filter cycle (using 3 or 4 common cycles)—see Figures A1 and A2. This is true for almost all economies. This result is not an inevitable outcome of the methodology-recall that there are 3 common cycles and it is conceivable that some economies would have exposure to some cycle, but not others. However, with this sample of countries, it appears that the exposure to these common cycles is similar. The results are stronger, but also similar in terms of the ranking of countries, to the correlations of growth rates. Costa Rica, El Salvador, and Honduras appear to be the most sensitive to the U.S. business cycle. 
Figure 4. Central America: Cyclical Components of GDP, 1960-2006 1/
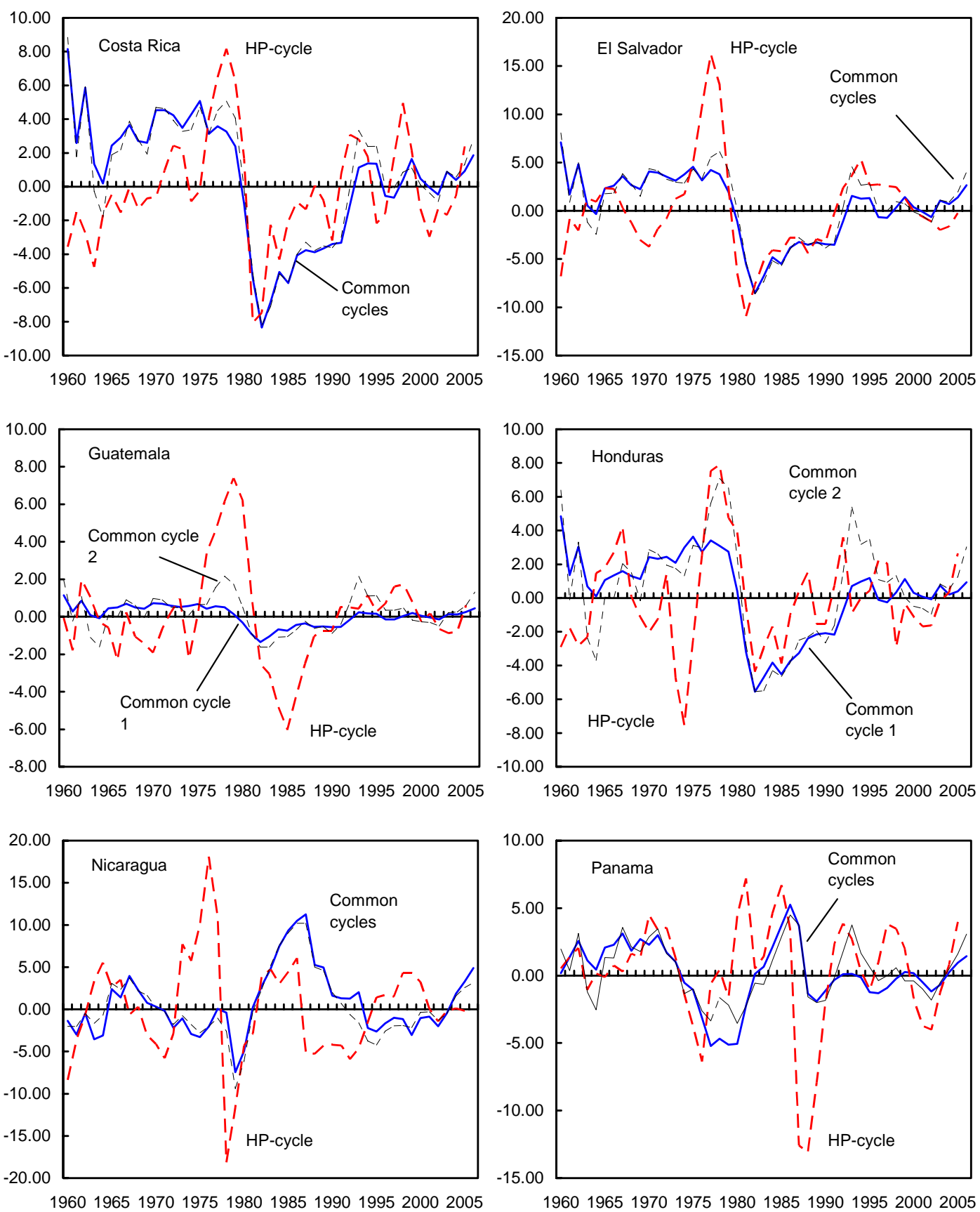

Source: Author's calculations.

$1 /$ There are two cyclical components from the common cycles model for each country. Cycle 1 is estimated from a model with 4 cofeature vectors (i.e. 3 common cycles and 4 common trends). Cycle 2 is estimated from a model with 3 cofeature vectors (i.e. 4 common cycles and 3 common trends). 
Figure 5. Central America: Trend Components of GDP, 1960-2006 1/
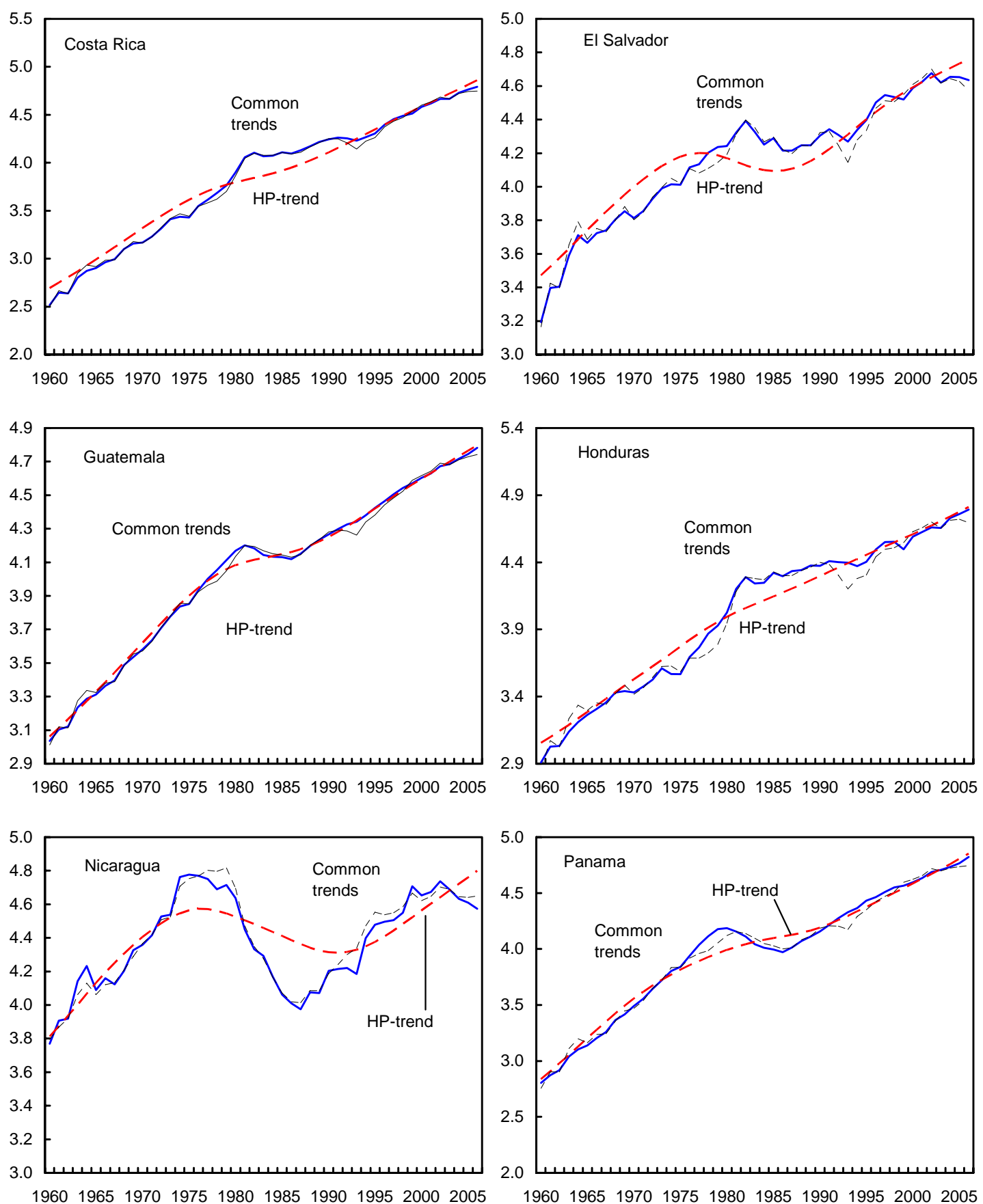

Source:Author's calculations.

$1 /$ There are two trend components from the common cycles model for each country. Trend 1 (solid line) is estimated from a model with 4 cofeature vectors (i.e. 3 common cycles and 4 common trends). Trend 2 (broken line) is estimated from a model with 3 cofeature vectors (i.e. 4 common cycles and 3 common trends). 
Figure 6. Central America: Average Correlation of Cyclical GDP Component to the United States - Comparison of Methods 1/
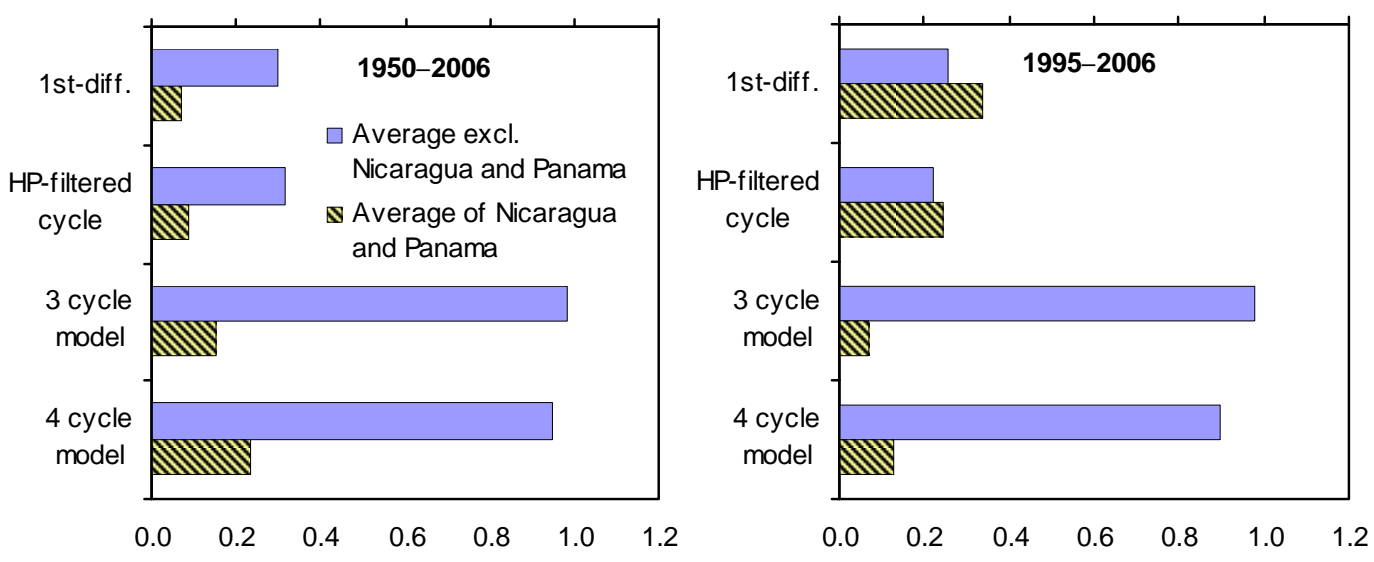

Source: Author's calculations

$1 /$ The methods include first-differenced log values, the first difference of the cyclical component from the Hodrick-Prescott filter, and the first difference of the common cycle factor recovered from the Vahid and Engle (1993) decomposition.

\section{E. Cyclical and Trend Elasticities to the United States}

In our sample, we reasonably assume that we have one truly exogenous cycle, that of the United States (ignoring, for now, the possibility of common exogenous shocks, which could characterize the 1970s oil supply disruptions). While correlations show that the cycle in most Central American countries and the U.S. tend to move in the same direction, it does not tell us anything about elasticities; i.e. how much growth in Central America would respond to a cyclical shock in the U.S. Assuming one-way causality from the U.S. to Central America allows us to use very simple methods to estimate elasticities, without running into all of the interpretation and estimation problems related to endogenous regressors.

The cyclical contribution to GDP growth is approximated by the first difference in the cyclical series extracted above. Then, for each Central American country, the firstdifferenced cycle was estimated as the sum of: a constant $\gamma$ (which should be zero in the long-run); the first differenced U.S. cycle and the elasticity $\varepsilon^{U S C}$, the first differenced U.S. trend and the elasticity $\varepsilon^{U S T}$; and a residual $e$ that could reflect country-specific factors or linkages with other economies in the sample. Given our exogeneity assumption, this relationship—equation (x) below—may be estimated using ordinary least squares (OLS).

$$
\Delta y_{i t}^{C}=\gamma_{i}+\varepsilon_{i}^{U S C} \cdot \Delta y_{U S t}^{C}+\varepsilon_{i}^{U S T} \cdot \Delta y_{U S t}^{T}+e_{i t}
$$

Recall that the codependent combination of variables eliminate the influence of past shocks. As a result, we should be able to discard autoregressive terms or lags of the U.S. cycle. If such variables were incorrectly omitted from equation (x), the result would likely be strong serial correlation of the equations residuals, something that can be tested using well-known procedures. 
We find that Central American is very cyclically sensitive to the U.S., with elasticities highly significant for four countries. (Guatemala's elasticity is somewhat lower than the others, owing mostly to the low volatility of the historical GDP series.) In contrast, long-run trend shocks in the U.S. have a lesser impact, indicating that trends are determined much more by regional developments. Running diagnostics for each of these estimations confirms that the model is well-behaved and supporting our earlier assertions that this simple functional form captures the true cyclical elasticities (Table A5).

Table 4. U.S. GDP Growth Elasticities in Central America 1/

\begin{tabular}{lcccccc}
\hline & \multicolumn{2}{c}{$\begin{array}{c}\text { Elasticity of the } \\
\text { Cycle to }\end{array}$} & & \multicolumn{2}{c}{$\begin{array}{c}\text { Elasticity of the } \\
\text { Trend to }\end{array}$} \\
\cline { 2 - 3 } \cline { 5 - 6 } Country & U.S. cycle & U.S. trend & & & U.S. cycle & U.S. trend \\
\hline Costa Rica & $0.90^{* * *}$ & 0.02 & & 0.00 & $0.41 *$ \\
El Salvador & $1.07^{* * *}$ & 0.06 & & -0.23 & 0.44 \\
Guatemala & $0.17^{* * *}$ & 0.01 & & -0.05 & 0.11 \\
Honduras & $0.59^{* * *}$ & 0.00 & & 0.00 & $0.66 * *$ \\
Nicaragua & 0.41 & 0.36 & & -0.35 & -0.86 \\
Panama & 0.10 & 0.03 & & -0.10 & -0.35 \\
\hline
\end{tabular}

Source: Authors' calculations.

$1 /$ Elasticity of the cyclical and trend component of growth in each economy to the cycle and trend in the United States, with ${ }^{* \star},{ }^{*}$, and * implying significance at the 1,5 , and 10 percent levels respectively.

\section{F. Variance Decomposition by Factor}

How much of the variation in GDP is due to the trend and how much to the cycle, at least as we define them here? Previous research answered this question using a VAR approach (see Vahid and Engle (1993) and Cerro and Pineda (2000)). Generally, it was found that one type of shock completely dominates variance and, using the same methods, similar results are obtained using this sample. However, the shock that dominates is very sensitive to the ordering. Without strong priors from theory to suggest which shock should be ordered firste.g. cyclical or trend shocks-we have a powerful incentive to identify a new decomposition method.

We use an application of the portfolio risk contribution. To describe this method, first recall that in our case, there are 3 common cycles and 4 common trends, which are scaled up by the factor loadings to yield the level of GDP. This implies that it is possible to write GDP as a factor model, where the ( $n \times 1)$ vector $\mathbf{f}$ contains $r$ cycles and $s$ trends:

$\mathbf{y}_{t}=\mathbf{A f}_{t}$

For any individual country, this can be written as:: 
$y_{i t}=a_{i 1} f_{1 t}+a_{i 2} f_{2 t}+\cdots++a_{i n} f_{n t}$

The variance in this case can be written as:

$\operatorname{var}\left(y_{i}\right)=\sum_{j=1}^{n} \sum_{k=1}^{n} a_{i j} a_{i k} \operatorname{cov}\left(f_{j}, f_{k}\right) \quad \forall j, k=1, \ldots, N$

Our results indicate that for most Central American countries, the cycle contributes most to changes in GDP - see Figure 7. One exception is Honduras, for which the trend is more important and more closely linked to the U.S. trend than other countries. The other exception is Guatemala, with the cycle tending to dampen down changes in the trend; this can occur due to the inclusion of covariance terms in equation (16). Once again, as with the estimated elasticities, the curiously low volatility of the historical GDP series may be playing some role in this result.

Figure 7. Contribution of Cycle and Trend to GDP Growth (Common Cycles Method, 1950-2006)

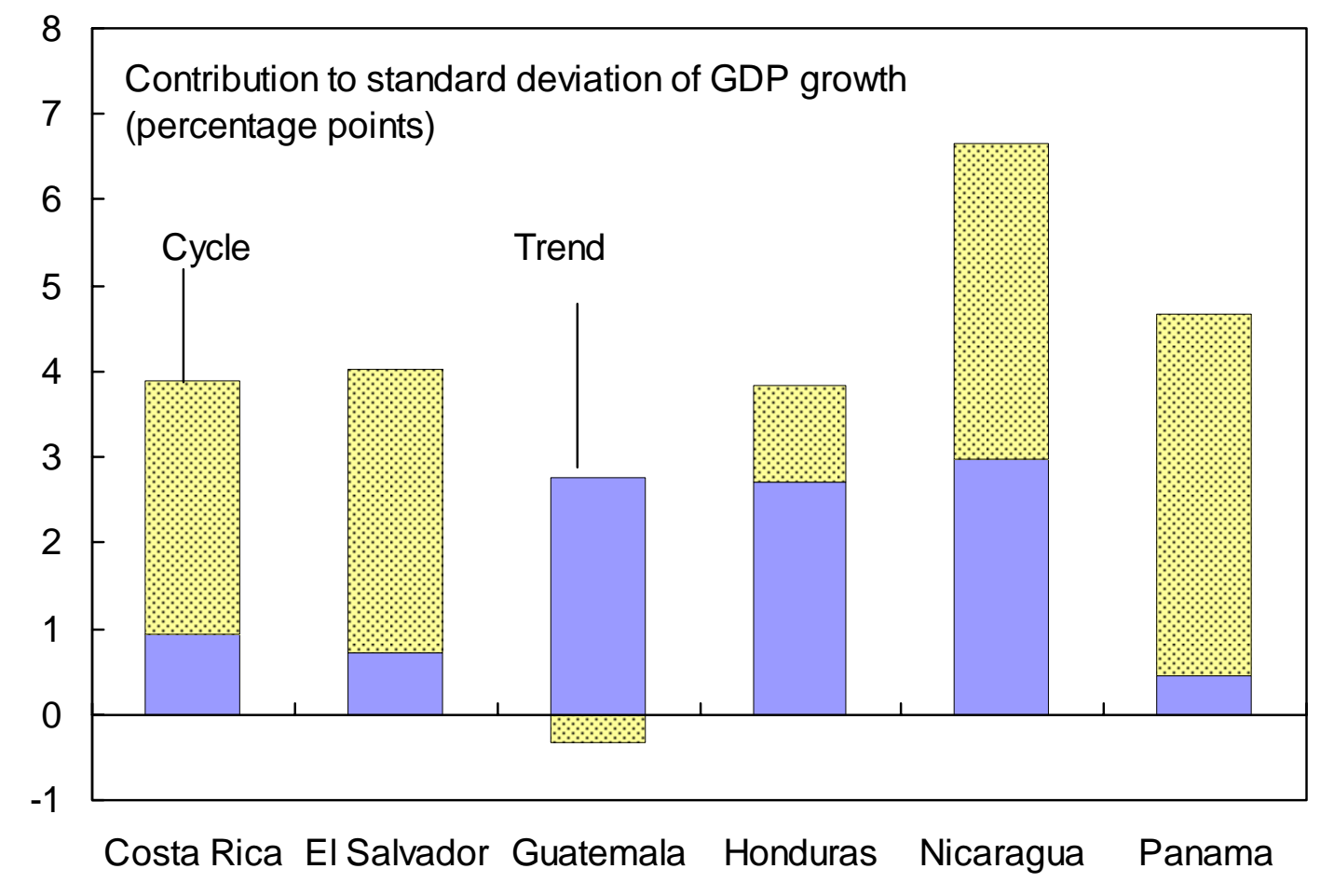

Source: Author's calculations. 


\section{SUMMARY AND CONCLUDING REMARKS}

\section{A. Cyclical Linkages-Stronger Than We Thought}

Almost all of the countries in our sample-including the United States—share a common business cycle. Clearly, the U.S. is the dominant economy and, as a result, we have evidence of a powerful cyclical linkage running from the U.S. to Central America, a linkage that is stronger than simple regressions of GDP growth rates would imply.

Indeed, growth elasticities using GDP suggest a much weaker cyclical relationship. This is due to the weak links between long-run growth shocks in Central America and the U.S., the most important of which are related to armed conflicts in particular countries but also common terms of trade shocks, and poor policy responses-see Macía, Meredith, and Vladkova Hollar (2007). If the long-run component of Central America's GDP growth is not stripped out, reflecting these shocks, estimated cyclical linkages with the U.S. will seem lower than they really are, which could complicate the policy response.

\section{B. How Will Linkages Evolve?}

How will these cyclical linkages between evolve? They are unlikely to weaken in the absence of a significant diversification of exports and investment inflows, beyond the U.S. and, perhaps, the region itself. The CAFTA trade agreement, the most important economic change in recent years, may play the pivotal role in determining how external linkages develop.

Most obviously, CAFTA may encourage more integration with the U.S. through trade, but also through investment flows and the financial sector. This would tend to strengthen cyclical linkages. For example, Mexico's experience under NAFTA suggests that trade flows between Central America and the U.S. could increase rapidly as a result of CAFTA, while FDI from the U.S. would rise (Kose, Rebucci, and Schipke (2005)).

However, it is also conceivable that CAFTA would have an externality effect that could weaken the dependence upon the U.S. cycle. It seems reasonable to assume that CAFTA could have a positive effect on productivity growth, through higher investment and technology transfer. This in turn could encourage investment from new sources that have not been a strong presence in the region, such as Asia. Improved competitiveness may also increase the region's penetration in other markets. In other words, CAFTA could have positive externalities beyond the obvious linkages with the agreement's members. Other bilateral trade agreements, including those currently being negotiated with the European Union, could also encourage cyclical diversification (Desruelle and Schipke (2007)).

The more difficult question is how long-run trend growth, which has been responsible for long periods of de-coupling with the U.S., will evolve across the region. The diversification of exports, with a greater share now destined for neighboring countries in the region rather than the United States, suggests that Central America may be experiencing its own growth dynamic. Perhaps this is the early stage of the positive externality process from CAFTA mentioned earlier. How could this provide some insulation against cyclical fluctuations in the U.S.? First, by encouraging linkages with new markets beyond CAFTA. Second, and less 
likely, by building the region's critical economic mass to the point that it could generate its own economic cycle.

\section{Policy Implications}

Whether a rise (or fall) in economic growth is due to the cycle or long-run structural factors should influence the public policy response. The clearest example is fiscal policy. Evidence suggests that government tax revenues in the region rise by more than one-for-one with growth in the economy. ${ }^{6}$ For example, if GDP growth over a year is 5 percent, tax revenues will grow by more than 5 percent, causing the tax-to-GDP ratio to rise (and vice versa for a decline). ${ }^{7}$

The decision to save or spend this additional income, is a straightforward application of the permanent income hypothesis. If the rise in growth is due to permanent structural factors, then the optimal response would be for the government to fully "spend" it, either through higher expenditure or lower taxes. ${ }^{8}$ If the rise in growth is cyclical, and by definition temporary, it would be optimal to "save" most of it, and spread the benefits of temporarily higher income through time. In other words, governments would be well advised to adjust their spending to the "structural" level of revenues; i.e. the level explained by potential or long-run growth.

Appropriate policy settings rely upon a good understanding of the nature of growth. While a simple trend-cycle analysis incorporating major trading partners cannot provide all of the answers, it does provide some important clues. For Central America, the message seems to be that if regional growth is picking up (or falling) at the same time as it is in the United States, then it is reasonable to presume that some portion of that improved growth performance is due to temporary cyclical factors.

\footnotetext{
${ }^{6}$ For instance, Cubero and Sowerbutts (forthcoming) find that, in the case of Costa Rica, the elasticity of tax revenues with respect to GDP is about 1.1 (and much higher than that for income taxes).

${ }^{7}$ Over the long run, the tax-to-GDP ratio should be expected to stabilize at some level, given an unchanged tax structure.

${ }^{8}$ Ignoring absorption capacity constraints in the economy for simplicity, which could imply other consequences from higher spending such as higher inflation and rapid real exchange rate appreciation.
} 


\section{REFERENCES}

Cerro, A.M. and J. Pineda, 2002, “Do common cycles exist in Latin American countries?,” Latin American Research Abstracts, No. 17, Dallas, Center for Latin American Economics, Federal Reserve Bank of Dallas.

Cheung, Yin-Wong and Kon S. Lai, 1993, “Finite-Sample Sizes of Johansen’s Likelihood Ration Tests for Cointegration,” Oxford Bulletin of Economics and Statistics, Department of Economics, University of Oxford, vol. 55(3), pp. 313-28.

Chinn, Menzie D. and Guy Meredith, 2005, “Testing Uncovered Interest Parity at Short and Long Horizons during the Post-Bretton Woods Era,” NBER Working Papers 11077, National Bureau of Economic Research, Inc.

Cubero, Rodrigo and Rhiannon Sowerbutts, 2007, “Growth Elasticities of Tax Revenues in Costa Rica,” IMF Working Paper (forthcoming).

Desruelle, Dominique, and Alfred Schipke, 2007, Economic Growth and Integration in Central America, Eds. Dominique Desruelle and Alfred Schipke (Washington D.C., International Monetary Fund)

Engle, Robert F. and Sharon Kozicki, 1993, “Testing for Common Features,” Journal of Business and Economic Statistics, American Statistical Association, vol. 11(4), pp. 369-80.

Fiess, Norbert, 2007, “Business Cycle Synchronization and Regional Integration: A Case Study for Central America,” The World Bank Economic Review Advance Access.

Gonzalo, Jesus and Clive W. J. Granger, 1995, "Estimation of Common Long-Memory Components in Cointegrated Systems,” Journal of Business \& Economic Statistics, American Statistical Association, vol. 13(1), pp. 27-35.

Gonzalo, Jesus, and Jean-Yves Pitarakis, 2001, "Lag Length Estimation in Large Dimensional Systems," Econometrics 0108003, EconWPA.

Hecq, Alain, 2005, “Common Trends and Common Cycles in Latin America: A 2-step vs. an Iterative Approach,” Computing in Economics and Finance 258, Society for Computational Economics.

Hecq, Alain, Franz C. Palm and Jean-Pierre Urbain, 2006, “Common cyclical features analysis in VAR models with cointegration,” Journal of Econometrics, vol. 127(1), pp. 117-141.

Ho, Mun S. and Bent Sorensen, 1996, "Finding Cointegration Rank in High Dimensional Systems Using the Johansen Test: An Illustration Using Data Based Monte Carlo Simulations,” The Review of Economics and Statistics, vol. 78(4), pp. 726-32. 
Johansen, Soren, 1988, "Statistical Analysis of Cointegrating Vectors," Journal of Economic Dynamics and Control, 12, pp. 231-54.

Kose, M. Ayhan, and Alessandro Rebucci, 2005, "How Might CAFTA Change Macroeconomic Fluctuations in Central America? Lessons from NAFTA,” Journal of Asian Economics, 16, pp. 77-104.

Kose, M. Ayhan, Alessandro Rebucci, and Alfred Schipke, 2005, "Regional Integration and Financial Systems Issues" in Central America: Global Integration and Regional Cooperation, Eds. Markus Rodlauer and Alfred Schipke (Washington D.C., International Monetary Fund)

Macía, José Brambila, Guy Meredith, and Ivanna Vladkova Hollar, 2007, Growth Performance," in Economic Growth and Integration in Central America, Eds. Dominique Desruelle and Alfred Schipke (Washington D.C., International Monetary Fund)

Morales, R. Armando and Alfred Schipke, 2005, "Regional Integration and Financial Systems Issues" in Central America: Global Integration and Regional Cooperation, Eds. Markus Rodlauer and Alfred Schipke (Washington D.C., International Monetary Fund)

Rapoport, Hillel and Docquier, Frederic, 2005, “The Economics of Migrants' Remittances,” IZA Discussion Paper, No. 1531.

Roache, Shaun K., and Ewa Gradzka, 2007, "Do Remittances to Latin America Depend on the U.S. Business Cycle?,” IMF Working Paper 07/273.

Stock, James, and Mark Watson, 1988, “Testing for Common Trends,” Journal of the American Statistical Association, 83, pp. 1097-1107.

Vahid, F., and R. F. Engle, 1993, “Common Trends and Common Cycles," Journal of Applied Econometrics, Vol. 8, No. 4., pp. 341-360. 
VIII. APPENDIX

Table A1. Real GDP Summary Statistics

(Using first-difference of log values, unless otherwise specified)

\begin{tabular}{lcccccc}
\hline & Sample & & & & \multicolumn{2}{c}{ Unit root test p-values 1/ } \\
\cline { 5 - 7 } & size & Mean & Std. Dev. & Skewness & Levels & Changes \\
\hline Costa Rica & 56 & 5.1 & 3.9 & -0.2 & 0.20 & 0.00 \\
El Salvador & 56 & 3.1 & 4.0 & -1.9 & 0.51 & 0.03 \\
Guatemala & 56 & 3.8 & 2.4 & -0.7 & 0.66 & 0.01 \\
Honduras & 56 & 3.7 & 3.8 & 0.0 & 0.20 & 0.00 \\
Nicaragua & 56 & 2.9 & 6.7 & -2.4 & 0.20 & 0.00 \\
Panama & 56 & 4.5 & 4.7 & -1.1 & 0.45 & 0.00 \\
United States & 56 & 3.3 & 2.2 & -0.5 & 0.81 & 0.00 \\
\hline
\end{tabular}

Source: Author's calculations

$1 /$ One-sided p-values from augmented Dickey-Fuller unit root tests with lags selected using Aikake information criteria.

Table A2. Vector Autoregression Lag Order Selection Criteria 1/ 2/

\begin{tabular}{ccccc}
\hline $\begin{array}{c}\text { Lag } \\
\text { order }\end{array}$ & $\begin{array}{c}\text { Likelihood } \\
\text { ratio }\end{array}$ & AIC & SBC & HQ \\
\hline 0 & $\ldots$ & -15.3 & -15.0 & -15.2 \\
1 & 703.9 & -29.4 & -27.3 & -28.6 \\
2 & 92.3 & -30.0 & -26.1 & -28.5 \\
3 & 80.4 & -30.8 & -25.1 & -28.6 \\
4 & 68.2 & -31.9 & -24.3 & -29.0 \\
5 & $\mathbf{8 3 . 1}$ & $\mathbf{- 3 5 . 2}$ & -25.8 & $-\mathbf{3 1 . 6}$ \\
\hline
\end{tabular}

Source: Author's calculations.

$1 /$ Bolded figures identify the lag order selcted by each criteria for the VAR in levels of all seven variables.

2/ The criteria include: small-sample adjusted log likelihood ratio test; Aikake information criteria; Schwarz-Bayes information criteria; and the Hanan-Quinn information criteria respectively. 
Table A3. Tests for the Number of Cointegrating Vectors - Probability Values

\begin{tabular}{|c|c|c|c|c|c|c|c|c|c|c|}
\hline \multirow{3}{*}{$\begin{array}{l}\text { Null } \\
\text { hypothesis }\end{array}$} & \multicolumn{4}{|c|}{ Trace test } & \multirow[b]{3}{*}{5} & \multicolumn{4}{|c|}{ Maximum eigenvalue test } & \multirow[b]{3}{*}{5} \\
\hline & \multicolumn{4}{|c|}{ Lag order } & & \multirow[b]{2}{*}{1} & \multicolumn{3}{|c|}{ Lag order } & \\
\hline & 1 & 2 & 3 & 4 & & & 2 & 3 & 4 & \\
\hline$r=0$ & 0.029 & 0.000 & 0.000 & 0.000 & 0.000 & 0.000 & 0.000 & 0.000 & 0.000 & 0.000 \\
\hline$r \leq 1$ & 0.045 & 0.003 & 0.003 & 0.000 & 0.000 & 0.001 & 0.000 & 0.000 & 0.000 & 0.000 \\
\hline$r \leq 2$ & 0.018 & 0.104 & 0.002 & 0.000 & 0.000 & 0.014 & 0.009 & 0.000 & 0.000 & 0.000 \\
\hline$r \leq 3$ & 0.508 & 0.130 & 0.057 & 0.001 & 0.000 & 0.266 & 0.055 & 0.006 & 0.000 & 0.000 \\
\hline$r \leq 4$ & 0.590 & 0.301 & 0.094 & 0.000 & 0.000 & 0.357 & 0.234 & 0.049 & 0.000 & 0.000 \\
\hline$r \leq 5$ & 0.317 & 0.439 & 0.242 & 0.000 & 0.000 & 0.327 & 0.421 & 0.229 & 0.000 & 0.000 \\
\hline$r \leq 6$ & 0.375 & 0.318 & 0.279 & 0.010 & 0.086 & 0.375 & 0.318 & 0.279 & 0.010 & 0.086 \\
\hline
\end{tabular}

Source: Author's calculations.

Table A4. Tests for the Number of Cofeature Vectors

\begin{tabular}{|c|c|c|c|c|c|c|c|c|}
\hline \multirow{3}{*}{$\begin{array}{l}\text { Null } \\
\text { hypothesis }\end{array}$} & \multicolumn{4}{|c|}{ Probability values } & \multicolumn{4}{|c|}{ Canonical correlation } \\
\hline & \multicolumn{4}{|c|}{ Number of cointegrating vectors } & \multicolumn{4}{|c|}{ Number of cointegrating vectors } \\
\hline & 2 & 3 & 4 & 5 & 2 & 3 & 4 & 5 \\
\hline$s>0$ & 0.9821 & 0.9866 & 0.9581 & 0.9464 & 0.94 & 0.95 & 0.95 & 0.95 \\
\hline$s>1$ & 0.9657 & 0.9619 & 0.8009 & 0.7509 & 0.85 & 0.91 & 0.91 & 0.91 \\
\hline$s>2$ & 0.6962 & 0.4756 & 0.2669 & 0.0597 & 0.73 & 0.76 & 0.85 & 0.85 \\
\hline$s>3$ & 0.1776 & 0.0904 & 0.0073 & 0.0001 & 0.66 & 0.66 & 0.75 & 0.81 \\
\hline$s>4$ & 0.0083 & 0.0020 & 0.0000 & 0.0000 & 0.55 & 0.62 & 0.63 & 0.72 \\
\hline$s>5$ & 0.0000 & 0.0000 & 0.0000 & 0.0000 & 0.37 & 0.39 & 0.47 & 0.50 \\
\hline$s>6$ & 0.0000 & 0.0000 & 0.0000 & 0.0000 & 0.22 & 0.23 & 0.27 & 0.29 \\
\hline
\end{tabular}

Source: Author's calculations 
Table A5. Growth Elasticity Models - Diagnostics

\begin{tabular}{|c|c|c|c|c|c|}
\hline & Observations & R-squared & DW-statistic & $\begin{array}{r}\mathrm{LM} \\
\text { autocorrelation } \\
\text { test } 1 /\end{array}$ & $\begin{array}{r}\mathrm{LM} \\
\text { heteroscedasticity } \\
\text { test } 1 /\end{array}$ \\
\hline \multicolumn{6}{|c|}{ Cycle equations } \\
\hline Costa Rica & 56 & 0.81 & 1.84 & 0.1435 & 0.0487 \\
\hline El Salvador & 56 & 0.73 & 1.92 & 0.2971 & 0.2034 \\
\hline Guatemala & 56 & 0.21 & 1.89 & 0.2332 & 0.1312 \\
\hline Honduras & 56 & 0.97 & 1.81 & 0.0887 & 0.0212 \\
\hline \multicolumn{6}{|c|}{ Trend equations } \\
\hline Costa Rica & 56 & 0.23 & 1.79 & 0.1435 & 0.0487 \\
\hline El Salvador & 56 & 0.40 & 1.43 & 0.2971 & 0.2034 \\
\hline Guatemala & 56 & 0.04 & 1.02 & 0.2332 & 0.1312 \\
\hline Honduras & 56 & 0.71 & 1.99 & 0.0887 & 0.0212 \\
\hline
\end{tabular}

Source: Author's calculations.

1/ Probability value of the test statistic if the null hypotheses (of no autocorrelation or heterscedasticity) were true. 
Figure A1. Central America: Average Correlation of Cyclical GDP Component to the United States - Comparison of Methods 1/
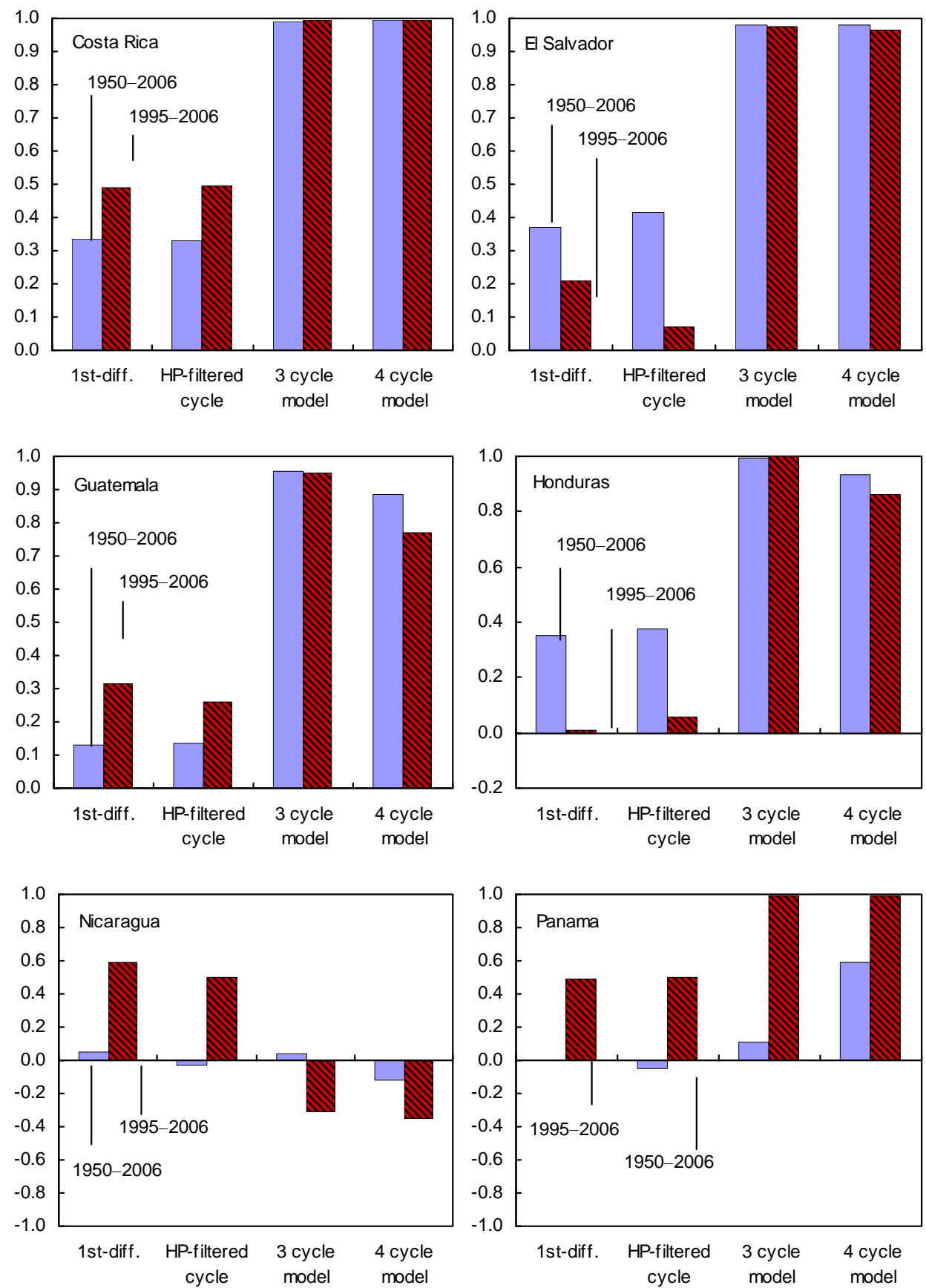

Source: Author's calculations

1/ The methods include first-differenced log values, the first-difference of the cyclical component from the Hodrick-Prescott filter, and the first difference of the common cycle factor recovered from the Vahid and Engle (1993) decomposition. 
Figure A2. Central America: Average Correlation of the Cyclical Component of GDP to Other CA Countries - Comparison of Methods 1/
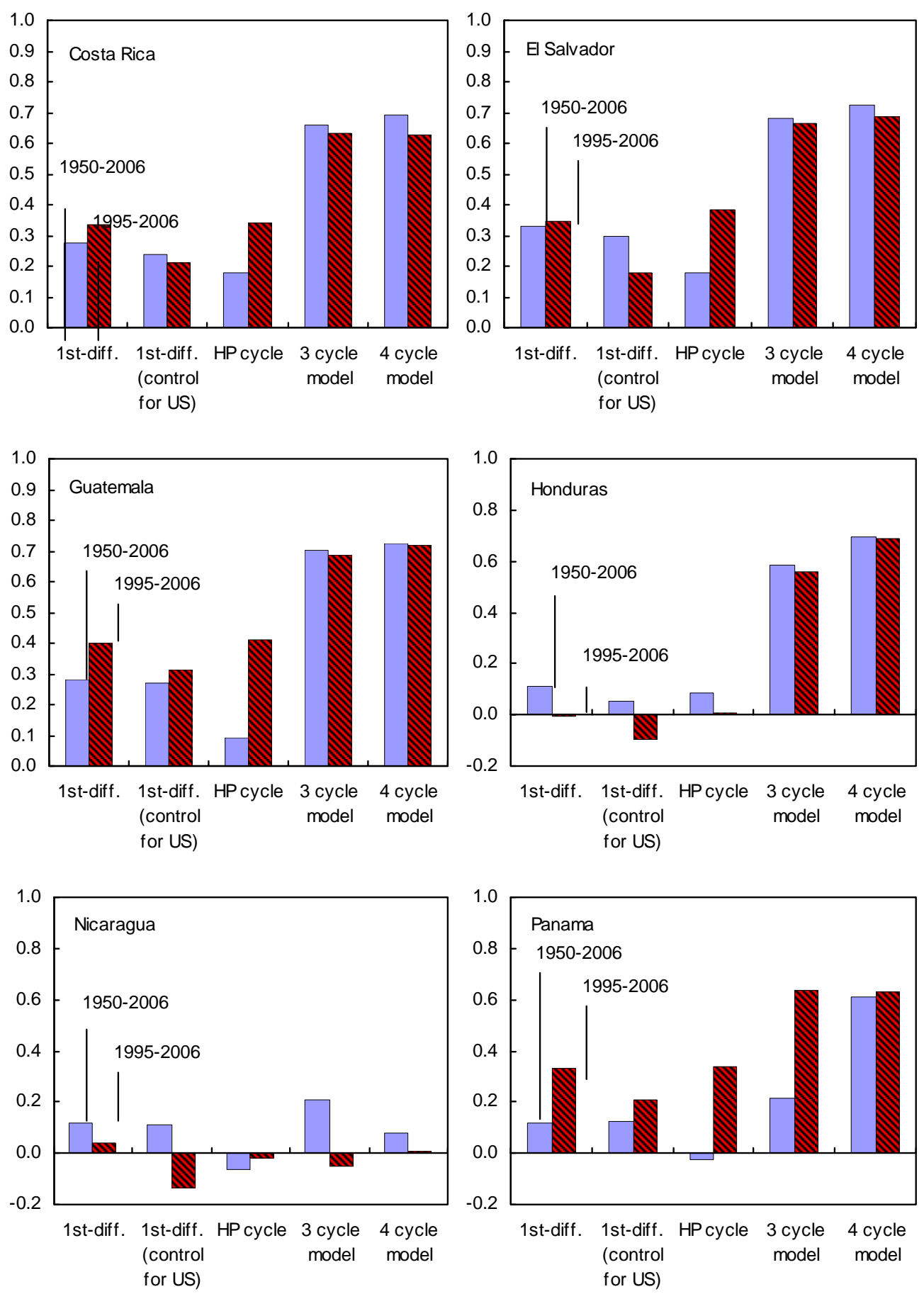

Source: Author's calculations

1/ The methods include first-differenced log values, first-differences adjusted for the U.S. effect by running an OLS regression on contemporaneous U.S. first differences, the firstdifference of the cyclical component from the Hodrick-Prescott filter, and the first difference of the common cycle factor recovered from the Vahid and Engle (1993) decomposition. 
Figure A3. Common Cyclical and Trend Factors
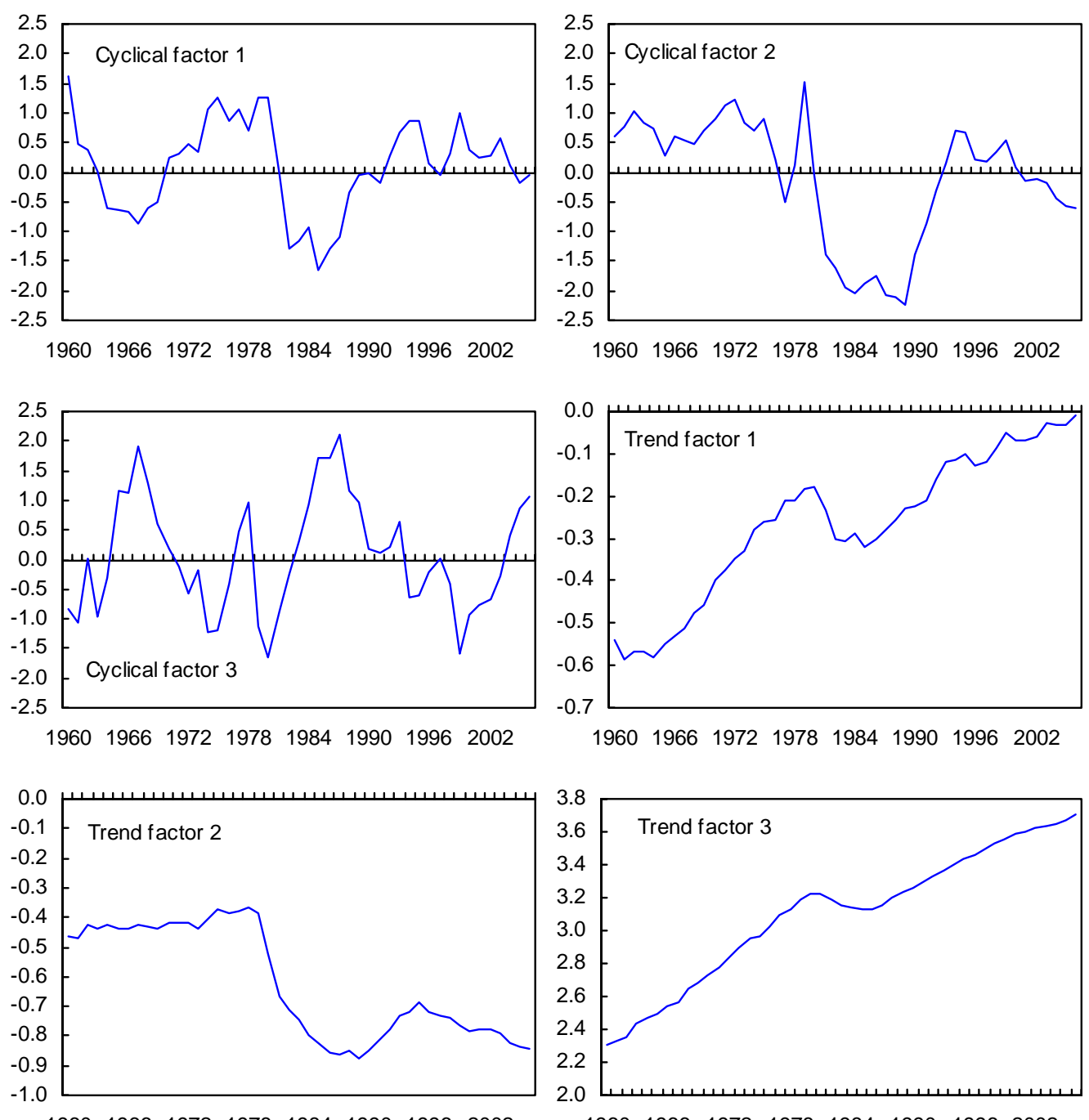

19601966197219781984199019962002

19601966197219781984199019962002

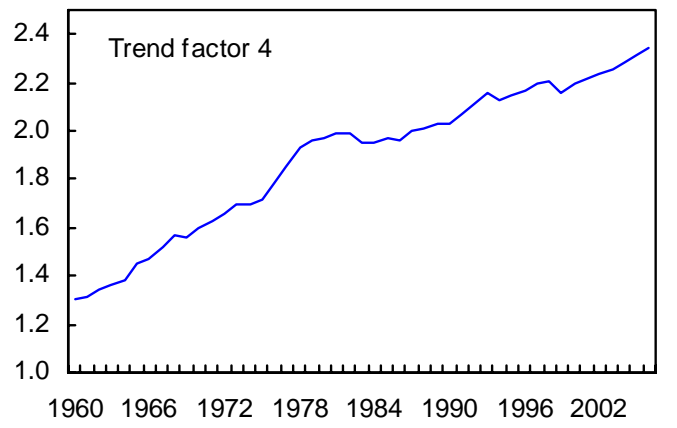

Source: Author's calculations. 